www.jmscr.igmpublication.org

Impact Factor 5.244

Index Copernicus Value: 83.27

ISSN (e)-2347-176x ISSN (p) 2455-0450

crossref DOI:_http://dx.doi.org/10.18535/jmscr/v4i9.25

Journal Of Medical Science And Clinical Research

\title{
Idiopathic Pulmonary Hypertension and Congenital Hypothyroidism: A Rare Case Report
}

\author{
Authors \\ Prof. Dr M.Senthilvelan ${ }^{1}$, Dr S.Senthilkumar ${ }^{2}$, Dr H.Resveen ${ }^{3}$, Dr P.Suganya ${ }^{4}$, \\ Dr Jayaram Kosalram ${ }^{5}$, Dr D.Kanagaraj ${ }^{6}$, Dr G.Sivachandran ${ }^{7}$, Dr G.Arulvenkatesh ${ }^{8}$ \\ ${ }^{1}$ Senior Professor, Rajah Muthiah Medical College \\ ${ }^{2}$ Postgraduate, Rajah Muthiah Medical College \\ ${ }^{3}$ Assistant Professor,Rajah Muthiah Medical College \\ ${ }_{4,5,6,7,8}$ Postgraduates, Rajah Muthiah Medical College
}

\begin{abstract}
Idiopathic pulmonary artery hypertension (IPAH) is a rare, progressive, debilitating and fatal disease of unknown etiology. Congenital hypothyroidism is a relatively common condition, and longstanding thyroid dysfunction has been reported as a cause for IPAH. We report a case of 20 year old female patient presented with features suggestive of congenital hypothyroidism, she was found to have severe primary pulmonary hypertension and was started on treatment. The possible mechanism of pulmonary hypertension in this patient is discussed in this case report.
\end{abstract}

\section{INTRODUCTION}

Idiopathic pulmonary artery hypertension (IPAH) is a rare, progressive, debilitating and fatal disease of unknown etiology. A delay in treatment can lead to decompensated right heart failure and death. Thyroid hormones play a major role in metabolism and hemodynamics of the human body. Congenital hypothyroidism is a relatively common condition1:4000, and longstanding thyroid dysfunction has been reported as a cause for IPAH. Thyroid function can also be affected in IPAH and RV dysfunction.

\section{CASE REPORT}

A 20 year old female was admitted with a history of difficulty in breathing and chest pain on and off for past 10 years, which got worse in past 1 month, patient was not able to do her regular activities as even minor physical activity caused her breathlessness and chest pain, which was relieved by taking rest, she had episodic palpitations and recurrent cough with occasional wheeze since childhood, she had difficulty in concentrating on things, lack of interest in the surroundings, loss of appetite, generalized puffiness of body, infrequent menstrual periods, easy fatiguability, dry skin and excessive hair loss. On detailed history taking her mother revealed she was born of non consanguineous marriage, at birth, there was no cry and had feeding difficulty, had poor suckling and was fed expressed milk, She had delayed milestones since childhood, poor performance in school and discontinued after $10^{\text {th }}$ grade. Her height has been the same since age 12, No history of heat or cold intolerance, Attained menarche at 18 years and had menstrual cycles only once in 4 to 5 months. 
On examination, she was conscious, oriented, cooperative, afebrile, her height was $138 \mathrm{cms}$ with normal upper and lower segment ratio, her intercanthal distance, hairline, ear levels, head circumference, body weight, BMI, were within normal range. Her skin was dry and coarse with sparse brittle hair, breasts were underdeveloped Tanner 3 and absent pubic and axillary hair Tanner 1, thyroid normal in size, vitals stable, no elevated JVP. On systemic examination her mini mental score was 25/30, low pitched delayed speech, slightly delayed deep tendon reflexes, on cardiovascular system examination, normal position apex beat, palpable $\mathrm{P} 2$, high pitched pan systolic murmur of grade 3/6 heard over the lower left Sternal border, Loud P2 was present. Her lungs and abdomen were normal.

\section{Investigations:}

Her hemoglobin level, total and differential leukocyte count, liver function tests, renal function tests, lipid profile and electrolytes were within normal limits. ECG- Right ventricular hypertrophy, Radiography of the chest- Cardimegaly, RV enlarged, prominent hilar vessels \& main pulmonary artery.Ultrasound abdomen: Bilateral small ovaries with few follicles.

Thyroid profile: T3-0.46 ng/ml, T4-1.96 ug/dl, TSH: >100uIU/ml

2D Echocardiography: Severe PAH, Grossly dilated RA \& RV, Grossly enlarged main pulmonary artery, RA-RV Pressure Gradiant $82 \mathrm{~mm} \mathrm{Hg}$, with severe Tricuspid Regurgitation. EF $42 \%$.

Enlarged main pulmonary artery

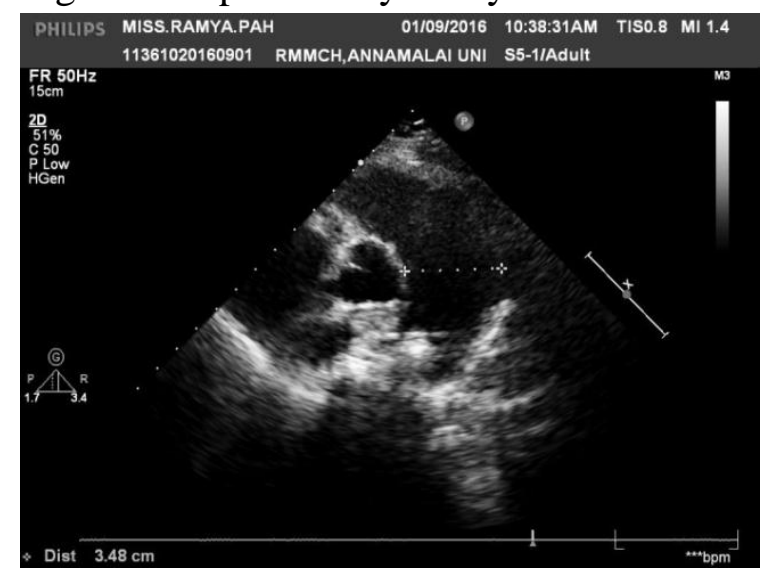

Grossly dilated RA \& RV and severe PHT

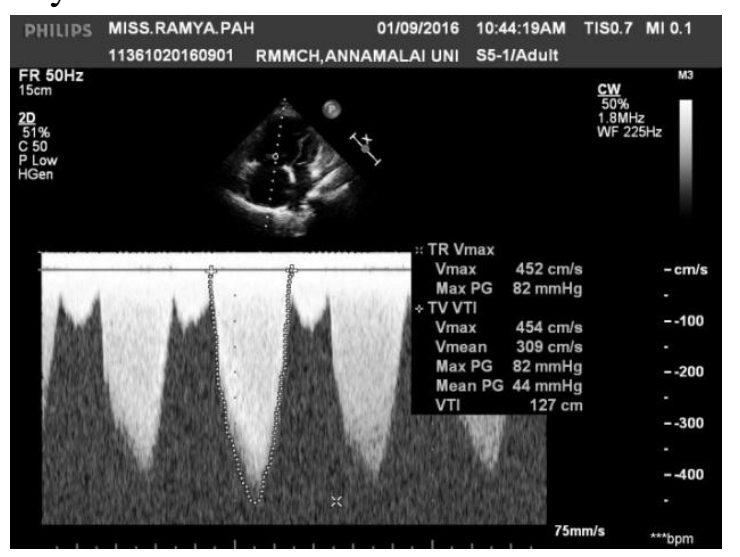

Severe Tricuspid regurgitation

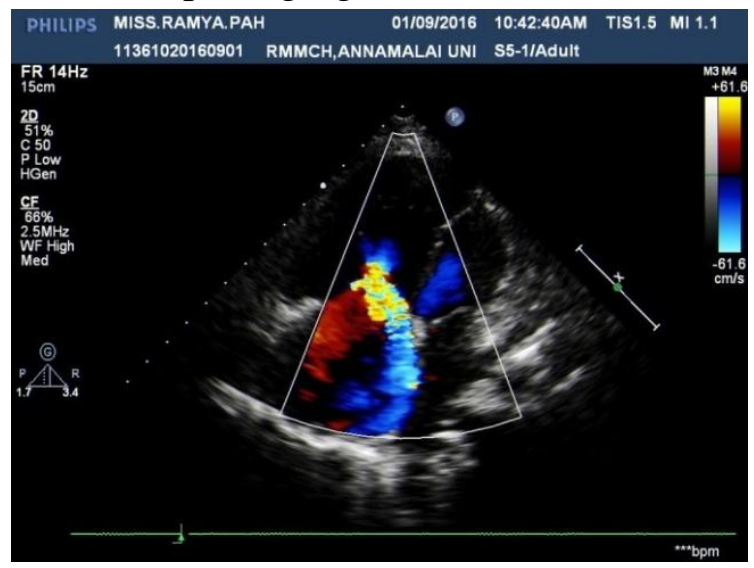

\section{DISCUSSION}

Pulmonary hypertension (PH) is a spectrum of diseases involving the pulmonary vasculature and is defined as an elevation in pulmonary arterial pressures (mean pulmonary artery pressure $>22 \mathrm{~mm} \mathrm{Hg}$ ). Pulmonary arterial hypertension (PAH) is a relatively rare form of $\mathrm{PH}$ and is characterized by symptoms of dyspnea, chest pain and syncope. If left untreated, the disease carries a high mortality rate, with the most common cause of death being de-compensated right heart failure.

The current classification system last revised in 2013 during the Fifth World Symposium on Pulmonary Hypertension, recognizes five categories of $\mathrm{PH}$

1. Pulmonary Arterial Hypertension (Idiopathic-IPAH) / Hereditary

2. Pulmonary hypertension due to left heart disease

3. Pulmonary hypertension due to chronic lung disease 
4. Pulmonary hypertension associated with chronic thrombo emboli

5. Pulmonary hypertension with unclear multifactorial mechanism

Idiopathic PAH is a very rare disease of unknown etiology, which can be confirmed when no significant heart disease, lung disease or pulmonary thromboembolism is found. A mutation in gene BMPR2, ALK, ENG is known to cause hereditary PAH.

Thyroid is an important organ with many metabolic and haemodynamic actions, and several cases of PAH have been reported in hypothyroid and hyperthyroid disorders. Thyroid function can also be affected in IPAH and RV dysfunction.

The association between PPH and Hypothyroidism may have an autoimmune basis, in view of the known association of both diseases with autoimmune diseases. In fact PPH is associated with autoimmune antibodies even in the absence of clinical autoimmune disease, and patients with both PPH and hypothyroidism have clinical evidence of connective tissue disease or positive serological markers of autoimmunity. There is a link between thyroid dysfunction and vascular reactivity, a phenomenon that may precede $\mathrm{PPH}$. Raynaud's phenomenon, which is seen in PPH, also occurs in hypothyroidism and improves with thyroid hormone supplementation.In an animal model, hypothyroidism has been shown to significantly affect the tissue levels of endothelin1 (ET-1), a potent vasoconstrictor peptide that may contribute to the pathogenesis of PPH. This association is clinically important because hypothyroidism is associated with hypoventilation and hypoxemia, which worsen coexisting pulmonary hypertension.

The small vasoactive peptide endothelin-1 (ET-1) has been shown to mediate the vascular remodeling of $\mathrm{PAH}$ by promoting vasoconstriction, smooth muscle proliferation, protein synthesis, and production of a variety of cytokines and growth factors. ET-1 activates a complex cascade of intracellular events by binding to its specific receptors, endothelin receptor $\mathrm{A}\left(\mathrm{ET}_{\mathrm{A}}\right)$ and endothelin receptor $\mathrm{B}$
$\left(\mathrm{ET}_{\mathrm{B}}\right)$. These receptors are distributed in a variety of cells and tissues in different proportions, suggesting a potential regulatory mechanism.

In patients with PAH, plasma ET-1 is increased and the elevated levels correlate with increased pulmonary vascular resistance and pulmonary arterial pressure, and decreased cardiac output. Furthermore, expression of ET-1 is increased in lung vascular endothelial cells of patients with PAH. Increased levels of plasma ET-1 and expression of pulmonary ET-1 have also been described in animal models of PAH.

It is a well established fact that endothelin (ET-1) is an important autocrine regulator of thyroid homeostasis and iodine metabolism. It binds specific endothelin receptors in the thyroid gland and alters its functional capacity. Alterations in endothelin levels play an important role in the pathophysiology of both pulmonary hypertension and hypothyroidism.

\section{CONCLUSION}

Pulmonary hypertension and thyroid dysfunction are two different diseases that often occur in conjunction as per the literature available. A significant number of PAH patients (30-60\%) have concomitant thyroid dysfunction. The exact mechanism in this regard is available only on theoretical grounds and has not yet been established and further studies are mandatory. Screening for thyroid function in all patients with $\mathrm{PAH}$ and vice versa have to be considered for an effective medical management, which may aid in significant improvement in patient's prognosis.

\section{REFERENCES}

1. Farber HW, Loscalzo J. Pulmonary arterial hypertension. N Engl J Med. 2004;351 (16): 1655-65.

2. Rubin LJ; American College of Chest Physicians. Diagnosis and management of pulmonary arterial hypertension: ACCP evidence-based clinical practice guidelines. Chest. 2004;126(1 Suppl):4S-6S.

3. Sociedade Brasileira de Pneumologia e Tisiologia. Diretrizes Brasileiras para 
Manejo da Hipertensão Pulmonar. J Bras Pneumol. 2005;31(Suppl 2):S1-S31.

4. Runo JR, Loyd JE. Primary pulmonary hypertension. Lancet. 2003;361(9368): 1533-44.

5. Ingbar $\mathrm{DH}$. The pulmonary system in thyrotoxicosis. In: Werner SC, Ingbar SH, Braverman LE, Utiger RD. Werner and Ingbar's The Thyroid: A fundamental and clinical text. Philadelphia: Lippincott Williams and Wilkins; 2000. p. 340-350.

6. Nakchbandi IA, Wirth JA, Inzucchi SE. Pulmonary hypertension caused by Graves' thyrotoxicosis: normal pulmonary hemodynamics restored by (131)I treatment. Chest. 1999;116(5):1483-5. 